\title{
Effective Resources Management in Construction Industries for Success
}

\author{
Jayakumar Muthuramalingam \\ School of Engineering and Science, Curtin University Technology \\ Sarawak Campus, CDT 250, 98009, Miri, Sarawak, Malaysia \\ Tel: 6-085-443-827Ｅ-mail: m.jayakumar@curtin.edu.my
}

\begin{abstract}
In most of the cases, the only poor planning and control of resources makes the projects plunge into crises. The ultimate aim of success or profit of the projects is achieved the objectives of specified performance of scope with in the stipulated time by utilizing minimum resources. Today's open market demands not only cheaper products and services but also better product and services. Increased pressures to reduce the cost have not only led to the migrations of U.S. manufacturing operations to Mexico and Far East but also Singapore and Malaysian manufactures into China and other Asian Countries. The process-based project management system controlled by the quality standards may be viable solutions for the success. In construction sector, rather than adopting the optimum design procedures, the effective construction methodology and planning will result in significant savings in resources. This paper describes the line of balancing techniques to minimize the quantity and maximize the productivity of human resources. The effective utilization of resources by establishing average demand over the maximum project periods by resources smoothening techniques are outlined in this paper.
\end{abstract}

Keywords: Resources controlling, Process management, Line of balance, Resources smoothening

\section{Introduction}

Definition of project is "A unique temporary process of definite start and end, comprising controlled activities achieving objectives which conform to constraints of time, cost, resources, quality, safety and environmental protection". Process means "A set of interrelated or interacting activities which adds value to inputs and converts them to acceptable outputs". Procedure (Design and Construction) means "A specified way of carrying out a series of processes to achieve a defined objective" (Les west, 2001). The general scope of any project of same categories may almost be the same but uniquely different only by the constraints which may directly or indirectly have impact on the design and construction process.

\section{Process Management}

7C's of Process Management Principles (Mike, 2007):

1. Consistency of Purpose between process and external stakeholders. The process exists to meet their needs and expectations.

2. Clarity of Purpose between process objectives and consequent actions and decisions.

3. Connectivity of Objectives so actions and decisions deliver outputs that achieve process objectives.

4. Competency of people and capability of equipment.

5. Certainty of Meeting Results through sound measurement and review against targets.

6. Conformity to Best Practices of work performance

7. Clear Line of Sight that process meets customer needs and expectations. Where it doesn't is cause for continuous improvement.

It is a systematic method connecting organisational activities and resources in order to achieve valued objectives and results shown in Fig.1. 


\section{Parties involved in construction projects}

In general most of the construction contracts are executed by mainly two types of contracting systems such as "construct only" contracts and "design and construct" contracts commonly known as "turn key" projects. The major parties involving in construct only contracts are client, consultant and main contactor may be with some specialised sub contractors. In design and construct contacts, main parties involved are only client and main contractor. Normally in this type of contacts there will be a competent person or a firm nominated as work superintendent by the client. Design engineers or a firm may be engaged by the main contractor as their sub contractors. In execution of the same project, each parties involved will have a different critical objectives to be controlled for their success.

Client's objectives:

- $\quad$ Complete and achieve all the indented scope of projects

- $\quad$ Achieve the project completion within the proposed time line

- $\quad$ Mobilize the required cash flow for the entire project as budgeted

The critical objective for the client is only the finance requirements and to meet cash flow needs for the completion of project. The nominated consultant or superintendent will assist to achieve the other two objectives.

Consultant's objectives:

- $\quad$ Achieve all the scope of works as specified and designed

- $\quad$ Control and maintain the progress as planed

- $\quad$ Control and minimize the variations in the projects except due to the additional scope of works

All are critical and only service oriented activities which are not involved with any requirements of resources mobilisations.

Contractor's objectives:

- $\quad$ Achieve all the scope of works as specified and detailed

- $\quad$ Control and maintain the progress as proposed and approved

- $\quad$ Mobilise all the required resources to achieve the completion of project within the given time line

- $\quad$ Control and minimise the resources required to execute all the scope of works by suitable construction methodology and planning

The main contractor is the only party responsible and directly involved to execute all the scope of works. They are the only real productive parties. This paper describes the role of resources managements and its importance for the success of the contractor in the construction sector.

\section{Process based project management system}

1. Management Responsibility

2. $\quad$ resource management

3. Product realisation

4. Measurement, analysis and improvement

The above are the main elements of the process based quality management system for the continual improvements (ISO 9001, 2000). The proposed effective process based management system to construction industries is shown in Fig.2. In this project management and resource management may be attached with corporate level or organization depending on the size of the projects but construction management should be effectively site based.

\section{Project Management Framework}

Design and Construction of civil engineering projects within schedule of time and budget by considering all the constraints (time, scope and cost) encountered during the execution is a great challenge. In the project management, project planning is the first key towards the success in construction, as it determines the time and sequence of the activities in the project, combines them to give an overall completion time. One of the objectives of Project Management Institute Malaysia Chapter (PMIMY) is providing framework for standardised project management requirements (Wong and Jayakumar, 2007). The following section describes the proposed framework for road construction in Malaysia. The steps in the framework include the scope of works, construction activities, consequences and resources controlling, shown in Fig.3.

\section{Line of Balance}

The overall quantities of the components are determined from the drawing and estimated calculation. If the quantity of 
the components is very large or little, the alternative construction methodology may be considered, as the alternative methodology may give better solution than the general methods that usually employed. The activities are subdivided into few sections based on the site constraints. It is used to arrange the activities to be executed in different location in an order, rather than waiting for the entire precedence activities to be completed first. Once the activity is completed in one section, the activity can be repeated in the next section.

The resource usage is kept as minimum as possible, since the activity is arranged to be executed with longer time but still can be completed within the completion date. Indirectly, it can help in the resource management by increase the efficiency of the resources because the labour is kept repeat doing the same work through out the project. Furthermore, the subdivision can help in reducing the cost, as the resource mobilisation cost can be reduced. The skill and human sources are considerably increased by achieving the on job experiences from repeatedly doing the same tasks (Chang and Ive, 2007).

The Fig.4 shows the principle of line of balancing technique. In Ladder A, two groups are required with Group 1 working on units $1,3,5$, etc and Group 2 on units 2 , 4, etc. It is noted that no loss of time as each group moves to its next unit. In Ladder B, the two groups work on the same units as in Ladder B. However it is noted that apart from units 1 and 2 , each group has to wait before starting work on its next unit.

Although the line of balancing technique was developed prior to the introduction of Critical Path and Precedence diagram methods, the Line of Balance method can utilize these two methods to great advantage. The basic method assumes that the delivery for several respective completed activities is expressed as a uniform Rate of Delivery or as uniform Handover Rate for the whole project or section of a project, as an example, four sections of a road per month or three foundations per week. The typical illustrative example of line of balancing technique recommended for housing projects is shown in Fig.5.

\section{Team Productivity}

The resource teams for each activity task are formed so that the efficiency of resources is increased while repeatedly doing the same task (Chang and Ive, 2007). The productivity of each team is called team productivity. The team productivity can be getting from the methodology databases, research observations, case studies, experiments, and etc. Team productivity is depending on the combination of machinery and manpower. Hence, the productivity for both machinery and manpower are determined respectively. After that, an optimum team capacity may be obtained by merging a reasonable, logic amount of manpower and machine. It is also called optimum labour/machine ratio (Wong and Jayakumar, 2007).

The general machinery productivity is estimated using the formula stated as below:

$$
\text { Machinery productivity }=\frac{\text { output of machinery }}{\text { time used }}
$$

The manpower productivity is determined by using the formula stated as below:

$$
\text { Manpower productivity }=\frac{\text { output of manpower }}{\text { time used }}
$$

\section{Resource and minimum Productivity}

The resource productivity is the productivity chosen in order to execute the job. In planning management, the resource productivity is always greater than minimum productivity required to complete the task. The minimum productivity is the lowest productivity in order to complete the work on time. Based on the detail discussion with project team, the duration for each activity is determined by the project manager or planner. The duration is subjected to the project methodology and the techniques for estimating activity duration, varied from one situation to another, depending on the type of work, the scheduler, and other factors. The project manager needs to consider the condition of contracts, risks, confidences, complexity of works, unexpected risks, latent condition, resource constraints and etc.

$$
\text { Minimum productivity }=\frac{\text { total quality or amount }}{\text { duration used }}
$$

Next, the number of team needed for each activity is determined by the following equation.

$$
\begin{aligned}
\text { Number of team } & =\frac{\text { Minimum productivity }}{\text { Team productivity }} \\
\text { Resource productivity } & =\text { number of resource } \times \text { team productivity }
\end{aligned}
$$

\section{Time Arrangement}

The total estimated duration to complete activities in each section is calculated based on the following equation. 


$$
\text { Estimated Duration }=\frac{\text { Quantity }}{\text { Resource productivity }}
$$

The duration needed to complete each activity in every section is added to become the total duration of completing that component. Next, the activities are put together in the logical relationship analysed from consequences analysis. The line of balance concept is used here by putting lead and lag duration in between two activities. By this way, the activities are overlapped together without affecting the progress, since both activities are done in different location. The total duration needed to complete scope of works involved in the project is determined. If the total duration exceeds the duration specified in the contract, the productivity of the critical activities has to be increased. It can be done either increasing the number of team or modifying the team resource. It is repeated until the project could be finished within the period specified. The computer software can help in calculating the total duration of the project. After the activities have been arranged, the resources are allocated to the activities. In the computer software such as Primavera, the resources can be assigned to the activities and the resources usage graphs are obtained for the reference.

\section{Resource Leveling and smoothening}

Resource leveling is done by delaying the activities when the resource usage at any time exceeds the resource availability. If the required resources exceed the resources available, the progresses of activities on that period are delayed proportionally. Resource smoothening is done by shifting the activities to the free float when the resource demand is high on that day. First, the resource usages are analysed and determine the peak resource usages. Later, the activities on that day are shifted by considering their free float. It is also done by shifting the daily uses of certain resources as uniform as possible to minimise the changeability. The illustrative example for resources smoothening is shown in Fig. 6 and 7.

\section{Costs of poor quality of work}

The poor qualities of works cost more for rectification of defects and make good during construction and after construction than the cost for providing and maintaining the required quality management system to avoid poor quality of works. Crosby has said that "Quality is Free" in that the money we spend on preventive measures should be more than returned in the elimination of waste effort and materials (Les West, 2001).

- The costs of poor quality during construction: Poor quality management while engaged in the work causes additional costs and resources for rework, failure analysis, re-test and re-inspection and for storing and disposing the Scrap.

- The costs of poor quality after construction: There are costs which may not been seen during the work but still have to be borne by the organization. These will include the cost for warranty, legal liabilities and loss of customers and potential customers.

\section{Case Study: Lumut Bypass}

The proposed Lumut-Seria bypass stretches for about $14.5 \mathrm{~km}$, within $3 \mathrm{~km}$ from the seashore (South China Sea). This region forms part of the wide alluvial flood plain of Belait and adjoining Baram river basins. On the Lumut end the site is characterized by the Pleistocene Liang formations, consisting of sand, sandy clay, clay and thin lignite seams overlain by delaic clay, coarse sand, lignite and tuffaceous clay and by Pleistocene Miri formation, consisting of sandstone, sandy shale and shale (Jayakumar, 2005). While only a small reach of this road, less than $1 \mathrm{~km}$ lies in this kind of formation, the major length of this road lies on the Quanternary clay and sand overlain by PEAT, spreading over the river basin. The contract title of the project was "Lumut Bypass Phase1", new alignment of $14.5 \mathrm{~km}$. This project consisted of two sections, 0 to $7500 \mathrm{M}$ and 7500 to $14500 \mathrm{M}$. The total contract period together for both the sections was 28 months. The contract sum was about 43.0 million Brunei dollars. Based on the geological conditions, the general scope of the work for phase 1 of the project was as below.

- $\quad$ Setting out and clear the vegetations.

- Removal of top peaty clay and unsuitable soil up to the depth instructed by the Engineer.

- Back fill with suitable granular fill up to design formation level.

- Construction of 19 Culverts on piled base.

- Construction of 3 Bridges including piled embankment for the Bridge over the BLNG pipe lines.

- Laying turf on both shoulders and side slopes along the entire length of the road.

The awarded main contractors, Dara Construction and Tong \& Tong divided the entire scope of the work into two portions as $\mathrm{CH} 0$ to 7500 and $\mathrm{CH} 7500$ to 14500 . Each contractor subdivided their portion into 10 smaller section of length approximately 750 meters and formed the team with required machineries and plants to carry out each task of the planned activities from section to section by using line of balance technique. Both contractors completed the assigned scope of the works very successfully within the time line with their estimated budget without much variation. A few 
project progress photos are shown in Fig.8 to 10 .

\section{Conclusion}

Control the resources to have the optimum utilization and have a minimum wastage al ways leads to the success of construction projects. This could be effectively achieved proper planning and resource management by using line of balance and resources smoothening techniques as well as by avoiding the poor quality of work resulting the heavy cost for rectifications and repairs.

\section{Acknowledgements}

Sincere acknowledgements to Mr. Abey Rathna, Project Manager, Dara Constructions, Brunei and Mr. Jai Mukund, Executive Director, J-Associates, India.

\section{References}

AS/NZS ISO 9001: 2000 “Quality management systems-Requirements”, pp. 24.

Chang, C. Y. and Ive.G, (2007), "The hold-up problem in the management of construction projects: A case study of the Channel Tunnel”, International Journal of Project Management, vol. 27, pp. 394-404.

David Redfern (2005) “Civil Project Control” Presentation for Civil Engineering, Curtin University, Perth, Australia, pp. $1-16$.

Jayakumar.M and Gajendra (2005), "Construction of highway in soft soil regions of Borneo" The international Conference ICCREM 2005, Penang, Malaysia, pp. 215-218.

Les West (2001), “Quality Management for Engineers” Presentation for Civil Engineering, Curtin University, Perth, Australia, pp. 126.

Mike Sodalini (2007), "Quality Control” Presentation-1 for Civil Engineering, Curtin University, Perth, Australia, pp. $1-24$.

Wong Chung Meng and Jayakumar. M. (2007), Project Management of Road Construction in Malaysia” Research report on Civil Engineering Project, Curtin University, Miri, Malaysia, pp. 115.

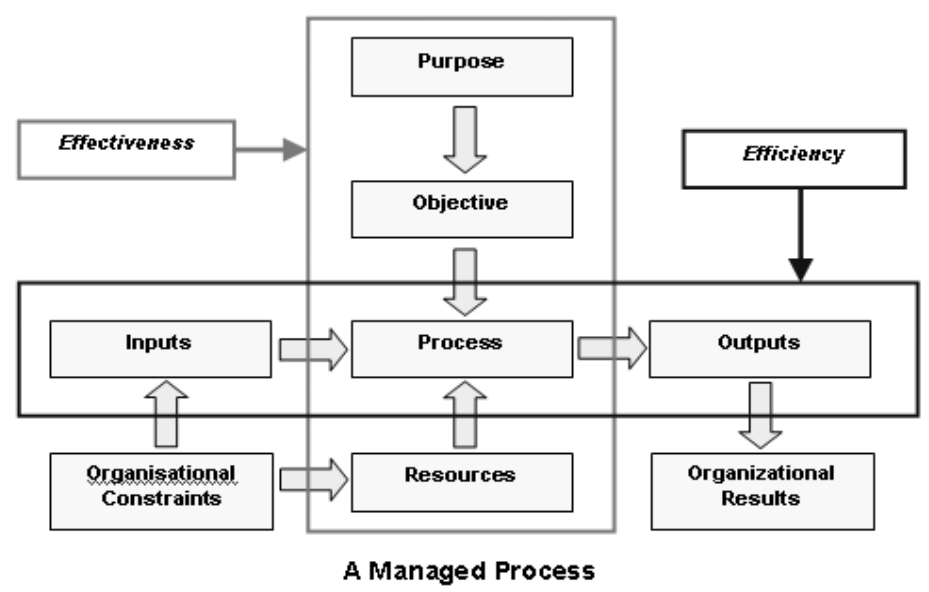

Figure 1. Process management 


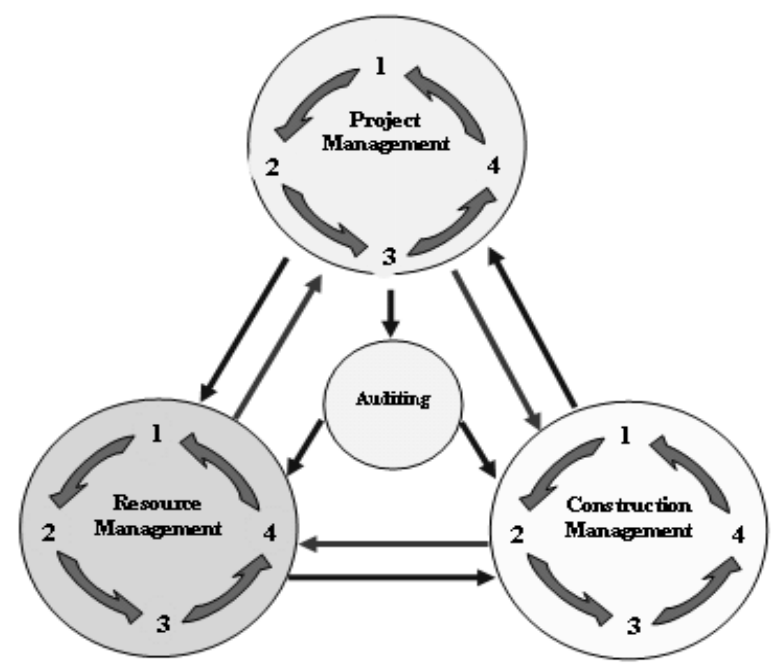

Figure 2. Process based project management system for construction sector

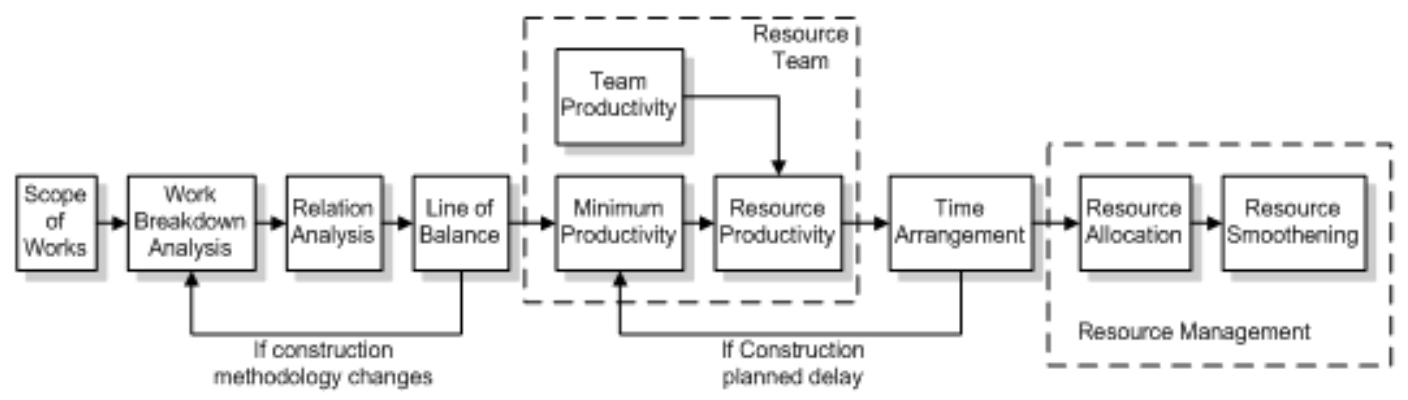

Figure 3. Illustration of Project Management Framework

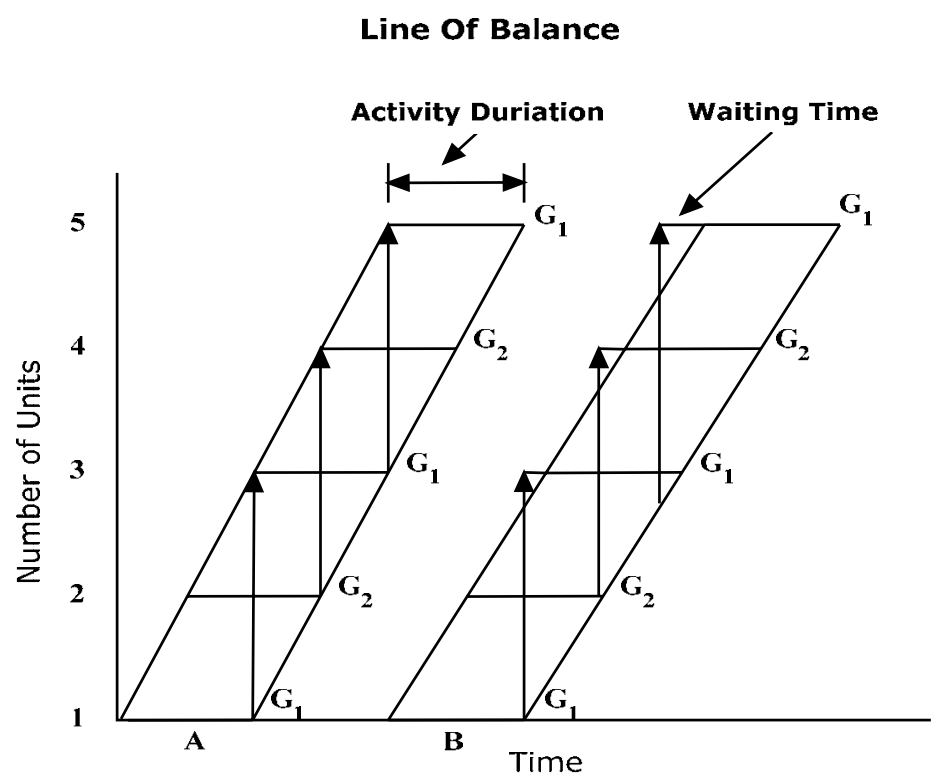

Figure 4. Line of balancing (David Redfern, 2005) 


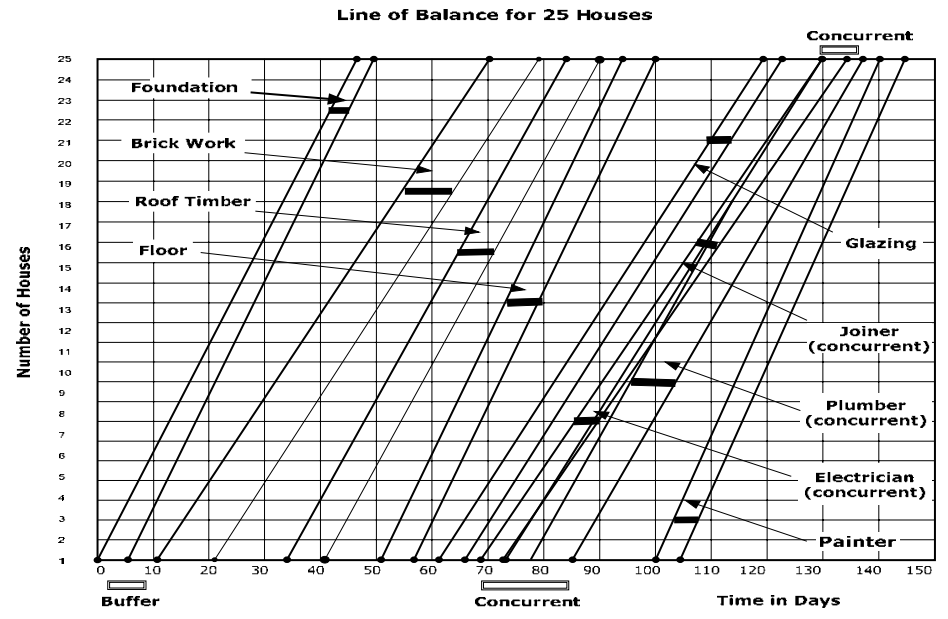

Figure 5. Line of balancing for housing projects

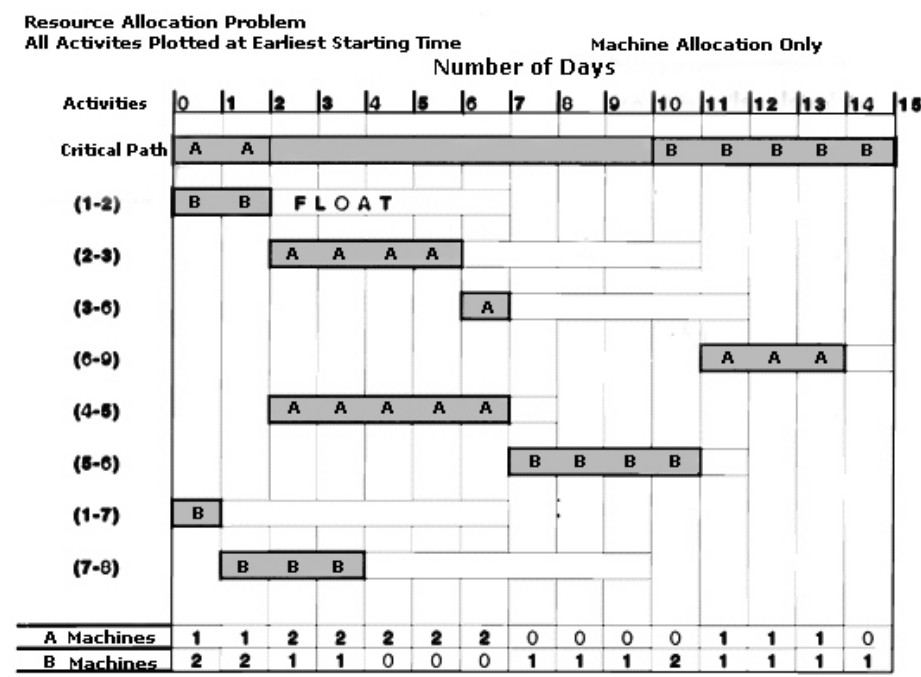

Figure 6. Machinery requirement before balance (David Redfern, 2005)

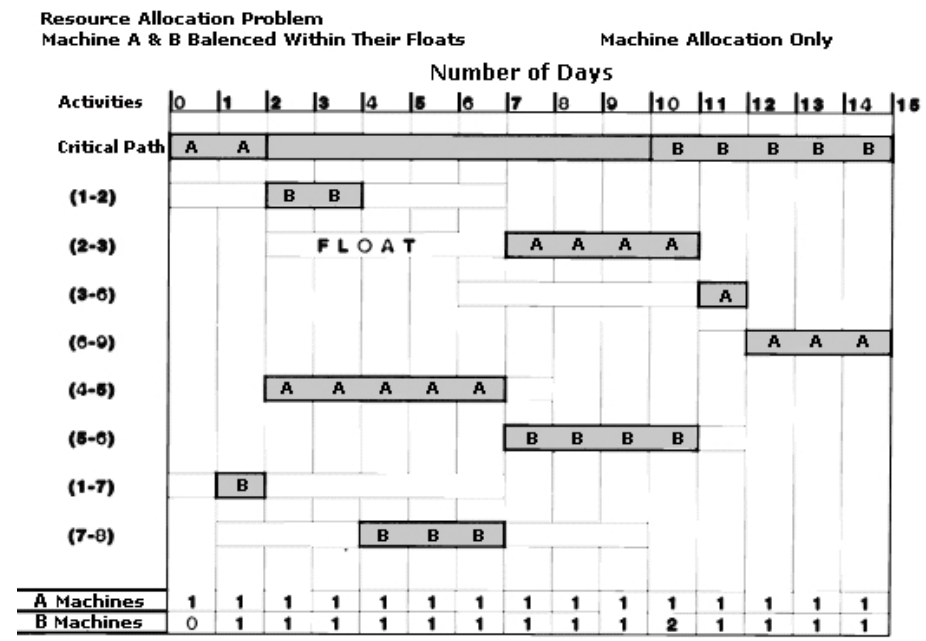

Figure 7. Machinery requirement after balance (David Redfern, 2005) 


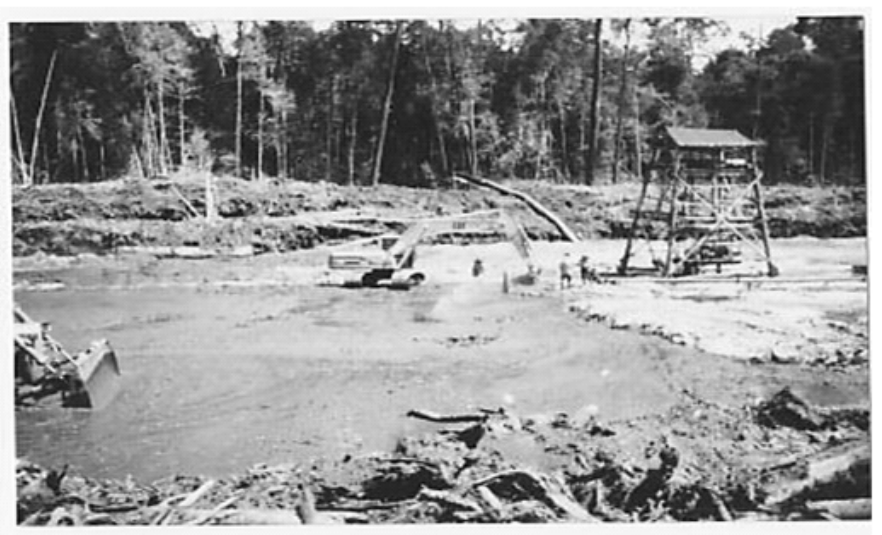

Figure 8. Installation of Slurry Pump

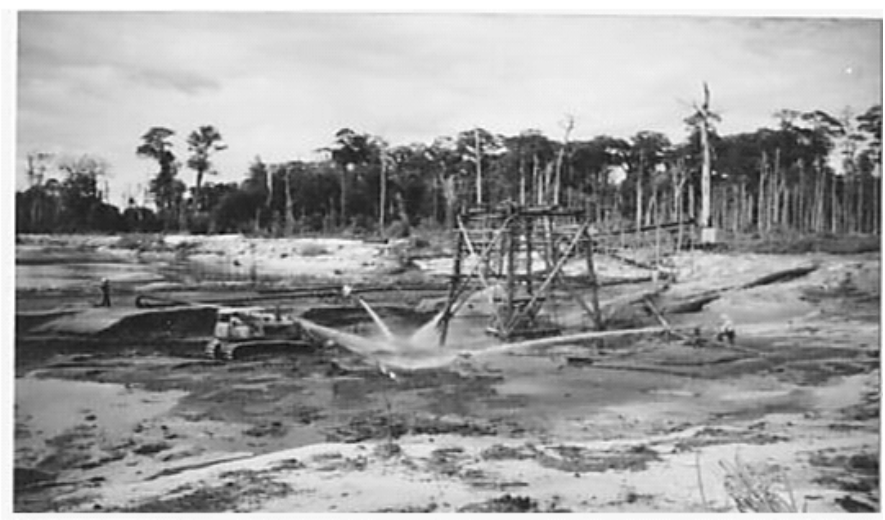

Figure 9. Jet Pumps melting the sand in Borrow Pits

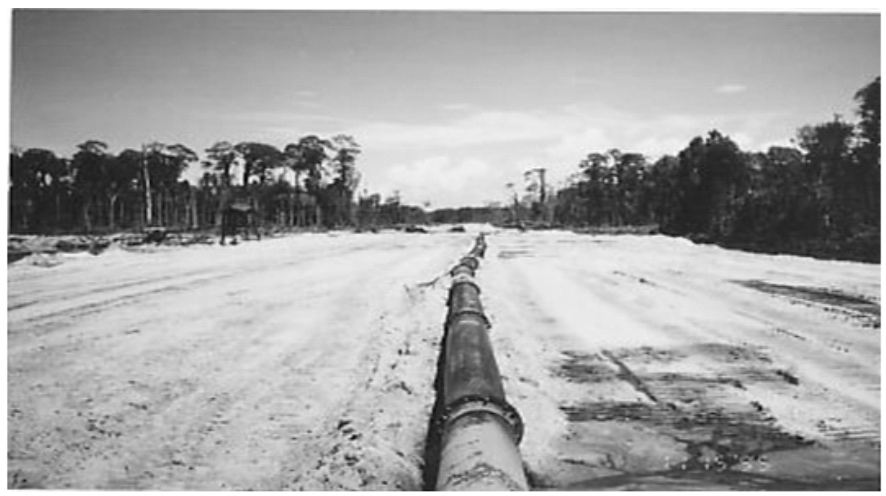

Figure 10. Completed stage of fill along with sand slurry pipe line 